\title{
Entomology-based methods for estimation of postmortem interval
}

This article was published in the following Dove Press journal:

Research and Reports in Forensic Medical Science

25 January 2016

Number of times this article has been viewed

\section{Michelle L Harvey' \\ Natalie E Gasz' \\ Sasha C Voss ${ }^{2}$}

'School of Life and Environmental Sciences, Centre for Chemistry and Biotechnology (Waurn Ponds Campus), Faculty of Science, Engineering and Built Environment, Deakin University, Geelong, VIC, ${ }^{2}$ Centre for Forensic Anatomy and Biological Sciences, School of Anatomy, Physiology and Human Biology, The University of Western Australia, Crawley, WA, Australia
Correspondence: Michelle L Harvey School of Life and Environmental Sciences, Centre for Chemistry and Biotechnology (Waurn Ponds Campus), Faculty of Science, Engineering and Built Environment, Deakin University, 75 Pigdons Road, Locked Bag 20000, Geelong, VIC 3217, Australia

Email michelle.harvey@deakin.edu.au
Abstract: Forensic entomology involves the use of insects and other arthropods to estimate the minimum time elapsed since death, referred to as minimum postmortem interval ( $\left.{ }_{\min } \mathrm{PMI}\right)$. This is based on the assemblage of insects found in association with remains, and most often, the time required for development of the first colonizing insects to develop to their size/ life stage at time of collection. This process involves the accumulation of appropriate data for the development of the species of insect at a variety of relevant temperatures and consideration of the other biotic and abiotic factors that may affect developmental rate. This review considers the approaches to the estimation of ${ }_{\min }$ PMI, focusing largely on the age estimation of specimens collected from remains and the limitations that accompany entomology-based PMI estimations. Recent advances and newly developed techniques in the field are reviewed in regard to future potential.

Keywords: forensic entomology, PMI, blowfly, decomposition, death investigation

\section{Introduction}

Forensic entomology, the use of arthropods as tools in legal investigations, primarily focuses on the estimation of the time length between death and the discovery of decomposing remains in cases of homicide, suicide, or accidental death. ${ }^{1-3}$ Termed "minimum postmortem interval" $\left({ }_{\min } \mathrm{PMI}\right)$, the entomological estimation of this time period is based on the assumption that insects, commonly found in association with decomposing remains, arrive at a carcass shortly after death. ${ }^{4}$ Decomposing remains present a transient habitat and food resource opportunity for numerous insect species. 5,6 Within hours of death, insect groups such as blowflies (Diptera: Calliphoridae) are olfactorily attracted to decomposing remains which are both a source of protein for egg development and a site for oviposition. ${ }^{7,8}$ The colonization time, development time, and departure time of the different insect species inhabiting remains are closely linked to the progression of carcass decomposition. ${ }^{9}$ As such, the age of the oldest immature insect specimen collected from remains, in the context of expected arrival time of adult females, provides an indication of the minimum time that the decomposing remains were available for insect colonization and thus ${ }_{\min }$ PMI. ${ }^{10-12}$

As insect development is primarily governed by temperature, where this relationship has been quantified for a species, the age of a specimen can be determined based on the level of development and the thermal history at which that specimen developed. ${ }^{13}$ Where immature insect specimens are not present or have already completed development, as is often the case in advanced stages of decomposition, ${ }_{\min } \mathrm{PMI}$ is estimated based on the assemblage of insects associated with the remains, referred to as the predictable 
process of insect succession. ${ }^{14}$ The insect species present are compared to known patterns of insect colonization and the time frames associated with each phase of colonization. Such estimates are not as precise as age-based estimates, but they do provide a broad time frame within which death occurred. ${ }^{15}$ Forensic entomology is most commonly used to provide ${ }_{\text {min }}$ PMI estimates where early colonizers are still in association with remains, and thus, the fundamental issue in such cases is to estimate the age of a specimen collected from remains. This review concentrates on the methods used to achieve this, considering the strengths and weaknesses of such approaches and scope for further research and technique development.

\section{Entomological approaches for age determination}

Current approaches to age estimation are based around the species-specific time required for an immature insect to progress through developmental landmarks such as length, weight, and life cycle stage in relation to temperature. While measures of developmental duration based on length and weight are valuable, life cycle stage is a preferred landmark for age estimation due to the confounding issues of diet, competition, and application of different preservation methods for forensic specimens (shrinkage) on weight and length. ${ }^{16,17}$ Thus, determination of specimen age is predominantly based on predetermined development data detailing the predictable relationship between temperature and insect growth for the onset and completion of each life stage of insect development. ${ }^{18-20}$ Applicable reference data details the duration of development of specific life stages of immature insects encompassing egg, larval instars, pupation, and eclosion under a range of constant or fluctuating temperatures. ${ }^{21}$ The application of data detailing the relationship between insect development and temperature is then used in several modeling approaches to predict insect specimen age based on the thermal history of the collected forensic specimens.

\section{Isomorphen and isomegalen diagrams}

The simplest approach is termed an "isomorphen diagram" which is essentially a scatter plot of the time from eggs hatching until eclosion plotted against constant temperature. ${ }^{1,22}$ Associated error bars provide a 95\% confidence interval for each developmental event. A slight variant, termed "isomegalen diagram", plots larval size since hatching (length, weight, or width) rather than life stages against temperature. ${ }^{22}$ Use of size as a component within the isomegalen diagram has the advantage of greater time point resolution compared to life stage event landmarks for age estimation; however, size measures have been reported as poor indicators of age. ${ }^{23,24}$

Estimation of specimen age is achieved with considerable accuracy where the thermal history of the specimens examined is consistent with the constant temperatures used to generate the reference data of the diagram. Considerable error occurs, however, in the derived age estimation using this approach when the ambient temperatures under which specimens are developing on decomposing remains fluctuate over time. ${ }^{22}$ As the majority of crime scenes within which decomposing remains are found experience fluctuating temperature conditions, a series of mathematical models have been developed which are generally more applicable and widely used.

\section{Thermal summation model}

The most commonly applied method for modeling insect development rates in a forensic context is the thermal summation model which applies a linear regression analysis to the positive relationship between temperature and development. ${ }^{1}$ Insect development can be measured at close intervals over a range of temperatures, and where the rate of development (measured as reciprocals of development time, 1/D) is plotted against temperature, a sigmoid-shaped curve results. ${ }^{25} \mathrm{At}$ temperature extremes, insect development is either slowed or completely halted corresponding to an upper and lower developmental threshold. ${ }^{26}$ A large proportion of the relationship between temperature and development is linear between the upper and lower developmental threshold (species specific). Linear regression can thus be used to determine an $x$-intercept (lower developmental threshold, $T_{\mathrm{L}}$ ) and inverse of the slope of the linear regression (thermal summation constant, $K$ ) which allow prediction of development time from the thermal history of a specimen. ${ }^{1}$ Under this linear regression model, development is measured as physiological time with units of "degree days" or "degree hours", where one degree day is equal to one degree above the lower developmental threshold over either 24 hours or 1 hour, respectively. Each life stage (egg, first instar, or pupation) requires a certain amount of accumulated degree hours to develop to the next life stage and complete development equating to $K .{ }^{26}$ Standard practice, under this method, would be to rear insects collected from a scene at a constant, controlled temperature, record time elapsed at point of eclosion, and subtract the physiological time required for laboratory development from the total physiological time required for development in this species. When used in conjunction with crime scene temperatures, the period of time elapsed between oviposition and insect collection at the scene may then be calculated. 
Problematically, while linear models have the advantage of simplicity and allow estimation of lower developmental thresholds and thermal summation constants, they do not incorporate the nonlinearity observed in insect development at low and high temperatures. ${ }^{27}$ Several alternative models have been proposed including a revised linear model ${ }^{28}$ that calculates an improved fit for $T_{\mathrm{L}}$ and $K$ by accounting for the high variability at extremes of the linear range and multiple nonlinear approaches ${ }^{29-31}$ encompassing a recent "new simulation model" termed "ExLAC". 32,33

\section{Curvilinear models/ExLAC}

Nonlinear or curvilinear models can more accurately describe the relationship between development and temperature for insect populations by incorporating the curvilinearity observed at the upper and lower temperature extremes of the plotted relationship between development rate and temperature. ${ }^{27,34}$ While offering improved parameters for estimation, the complexity of such models, however, reduces the practicality of application to forensic estimation of ${ }_{\min } \mathrm{PMI}$. Additionally, no one curvilinear model, above others, has been identified that consistently outperforms linear models across relevant species data. ${ }^{35}$

A recently proposed curvilinear model known as ExLAC has been demonstrated to offer an alternative to linear thermal summation modeling. ${ }^{32,33}$ While the ExLAC model shows minimal performance improvement over linear modeling, it has the advantage of generating error rates associated with the age estimate derived by the model. Again, the development model is based on the duration of each life stage during development as a function of temperature. ${ }^{33} \mathrm{An}$ individual exponential function is, however, applied to each life stage, and additional parameters are included in the model that account for variation in measurement of input values such as thermal history data and the strength of the relationship between life stage duration and temperature. ${ }^{32,33}$ The included measurement of error for the inputted temperature data offers a distinct advantage over the currently applied thermal summation model. Standard practice involves the use of temperature data gathered at the weather station nearest to the crime scene as a measure of the insect specimen's thermal history prior to collection. ${ }^{36}$ This data is corrected for potential variation between locations using regression modeling incorporating data acquired at the crime scene following the discovery of decomposing remains. While this aspect of the proposed model offers a measure of potential error in estimates of ${ }_{\min } \mathrm{PMI}$, the performance of the model is only marginally better than the linear thermal summation method for establishing specimen age. ${ }^{32}$ To date, the ExLAC model has yet to be thoroughly evaluated and assessed prior to implementation in forensic practice, and the linear thermal summation model is still the preferred method of estimating specimen age and thus ${ }_{\min }$ PMI.

\section{Current issues}

Regardless of the developmental modeling approach taken to determine age, several problems arise in regard to the available development data used in such models. Available reference data for use in forensic practice is typically focused on the development of early colonizing dipteran species. A considerable body of reference literature exists documenting the development of forensically relevant fly species under varied constant temperatures within the laboratory. ${ }^{11,37-41}$ Problematically, reference data is not available for all species reported in association with crime scenes, particularly in the case of alterative indicators of ${ }_{\text {min }}$ PMI such as beetles and parasitic wasps. Aspects of life history and development in relation to temperature are often unknown for specimens collected off remains or of limited scope for application in development models.

Additionally, research has indicated that populations of the same species can differ physiologically depending on their geographic origin. ${ }^{2,42,43}$ For instance, there are often considerable discrepancies in the reported development time of blowfly populations from different geographic origins when reared at the same developmental temperature. ${ }^{44,45}$ Such differences have been attributed to regional genetic variation between populations, although the effect of differing environmental factors between regions cannot be discounted. The possibility that inherent biogeographical variation exists between populations of species in relation to development time is of considerable consequence in respect to the accuracy of ${ }_{\min }$ PMI estimation. At present, development data for a species from a single source location are applied to the same species from different geographic locations, even though there is little evidence supporting the validity of such procedures and considerable evidence to the contrary. ${ }^{17,44}{ }^{46} \mathrm{At}$ present, the applicability of extrapolating development data to a population from a different geographic origin to that of the source data is likely to be called into question under cross examination during court proceedings. Thus, further work is urgently needed to address and quantify this issue.

Further error in the accuracy of ${ }_{\min } \mathrm{PMI}$ can arise in regard to a species physiological response to fluctuating temperature regimes, a common occurrence at crime scenes. Thermal summation assumes that a species development rate at a given 
constant temperature is independent of the overall thermal regime. ${ }^{47} \mathrm{~A}$ number of studies, however, have indicated that development rate under fluctuating temperatures does not correspond to development under the resulting mean constant temperature. ${ }^{24,48,49}$ As reference data detailing the relationship between temperature and insect development is typically generated using constant temperatures, the use of this data to model specimen age for forensic estimation of ${ }_{\min }$ PMI can lead to erroneous estimates where daily ambient temperatures at crime scenes fluctuate. As such, there exists a need for expanded research of species-specific development under both variable and constant temperatures to provide comprehensive reference data for use in forensic case work.

Moreover, temperature is considered the primary factor influencing insect development; however, a variety of abiotic and biotic factors additionally influence the rate of development including, humidity, ${ }^{50}$ photoperiod, ${ }^{51}$ and diet (nutrition). ${ }^{52-54}$ These factors are essentially ignored in the majority of studies documenting developmental timeframes for use in forensic practice, yet are likely to have an impact on development rate and hence the accuracy of any associated ${ }_{\min }$ PMI estimation. Other limitations in the currently available reference data include the lack of a standardized rearing methodology between research studies. Where development data is generated using different food substrates, photoperiods, sampling protocols (ie, sampling interval, larval density), and rearing conditions unrelated to temperature, reported development rates for a particular species often vary. ${ }^{55,56}$ Thus, inconsistency in the methodology behind the generation of development data for use in estimating forensic specimen age can contribute to inaccuracies in the associated ${ }_{\min }$ PMI estimate.

Estimates of ${ }_{\min }$ PMI based on modeling of the relationship between insect development and temperature are widely accepted in criminal courts throughout the world; however, there are substantial issues regarding the appropriateness of the reference data available in the literature and used to formulate such estimates. As such, further research on aspects of forensically relevant insect growth and life history are still needed to establish a comprehensive, global, reference database of applicable developmental data for use in both linear and nonlinear models.

\section{Recent advances in age estimation methodology}

Current approaches to age estimation are generally based on measurement of the timeframes associated with the start and end of the life stage collected, such as the onset of an instar or pupation. The duration of a life stage such as the pupal stage can be considerably long, and thus, the use of life stage landmarks alone (ie, onset of pupation and eclosion) as indicators of specimen age can introduce considerable error into associated ${ }_{\min }$ PMI estimates. ${ }^{57-59}$

Several approaches have been proposed to address this issue, and provide refined approaches to limiting the possible age range of a specimen. These range from observations of insect morphological features as an indication of age to quantitative approaches based on gene expression or hormone levels. These approaches vary in their utility, objectivity, and reliability.

\section{Morphology}

Calliphorids are the primary colonizers of carrion, and as such generally represent the oldest insects present on a corpse and perceived best indicators of ${ }_{\text {min }}$ PMI. They exhibit holometabolous development, meaning a complete metamorphosis through egg, larval, pupal, and adult stages occurs. These life stages are all morphologically distinct from each other. Within each life stage, relative degrees of development based on size or the relative level of development of certain features may be useful in characterizing the insects as having experienced a certain amount of physiological time. In the egg stage, which is relatively short, physical markers refining age estimates are less important than in the longer persisting larval or pupal stages. The pupal phase alone may comprise $>50 \%$ of the total life cycle of the insect; ${ }^{57-59}$ thus, the ability to refine an age estimate from a 2-week window, down to perhaps a 24- to 48-hour window, is highly desirable. Current approaches to pupal aging rely frequently on rearing to adult stage, ${ }^{60}$ at times a lengthy process and sometimes compromised by insect death due to the presence of hymenopteran parasitoids or other factors.

\section{External morphology}

Size measures are often proffered as useful methods to refine insect age within the larval stage, utilizing width, length, or weight of larvae as an indicator of relative period of development. ${ }^{61}$ These measures are subject to numerous influences, summarized suitably by Villet and Amendt, ${ }^{60}$ including drugs, maggot mass-generated heat, competition for food, substrate fed on, preservation, and measurement errors. These factors make the use of size measures, as used in isomegalen- and isomorphen-based methods, prone to significant error. An alternative is to concentrate on discernible developmental changes within a life stage.

Eggs, pupae, and adults display no obvious measurable size-related changes that may be utilized for age refinement. 
Eggs are generally reared to hatching, and then age is derived via back-calculation of physiological time required for development. Discernible morphological features are generally lacking unless the specimen can be observed to be in the process of emerging from the chorion via the plastron. In larvae, non-size-related changes are largely confined to the posterior spiracle morphology, with instar determined based on the number of slit-like openings to the trachea in each posterior spiracle. ${ }^{62}$ These instars are clear intra-life stage events that may be used to further refine larval age.

Adult age estimation is generally confined to the period immediately following eclosion, where wings are gradually unfurled as hemolymph moves into veins, and general body coloration of the fly develops. ${ }^{62}$ There is little call for determining age of adult flies, given that their mobility makes connecting them to development on a specific source of carrion problematic. The puparium left behind following eclosion is likely to provide as much information as the adult fly itself.

It is the pupal phase that necessitates the greatest age estimation refinement, given the extended duration of the stage and thus large timeframes provided for ${ }_{\min }$ PMI based on the landmarks of life stage commencement and end. In the pupal stage, there are few obvious changes on the exterior of the puparium itself, with the exception of the initial tanning and sclerotization process. ${ }^{62}$ Pupae are sedentary, and their extended close association with remains makes them useful targets for provision of temporal information regarding remains. It is for this reason that most age refinement methods concentrate on this extended stage.

The calliphorid pupa is coarctate, with the puparium formed following "loosening" of the third instar cuticle. The casing darkens with time, ${ }^{63}$ but coloration is obviously altered with soil type/moisture level and/or preservation. Removal of the puparium, however, reveals significant morphological remodeling as the larva metamorphoses to adult form, with the development of key features such as tagmosis, appendages, setae, and coloration. ${ }^{57}$ Examination of these features, in consultation with species-specific morphological timelines, ${ }^{57}$ may be utilized to refine an age estimate for a specimen. Brown et al ${ }^{57}$ utilized 23 morphological features of $\mathrm{Cal}$ liphora vicina pupae to refine an age estimate to within $5 \%$ of a pupa's actual age with 95\% reliability. This illustrates the utility of the technique for intra-pupal stage aging but is heavily reliant on appropriate datasets for numerous features in all species of relevance, and confirmation that between population variation is minimal, before data may be applied in other localities.

\section{Internal morphology}

Internal changes have been studied in the pupal phase of C. vicina for their use in age estimation of specimens. ${ }^{64}$ Internal metamorphosis during this phase involves histolysis and histogenesis of tissues and organs during the transition to adult form, with changes such as the utilization of larval fat bodies and glycogen stores. Thoracic flight muscles become recognizable, and digestive, reproductive, and nervous systems are modified and developed. ${ }^{64}$ These changes can be used to create a chronology of development relative to physiological time, and utilized, either alone or in conjunction with external morphological data, to provide a ${ }_{\min } \mathrm{PMI}$ estimate. Other life stages have not been considered, and future studies are needed to further develop this approach across relevant life stages.

\section{Optical tomography}

Optical coherence tomography utilizes benchtop-sized instrumentation to provide high-resolution images of samples without the need for destructive analysis. Specimens may be analyzed while still alive, remaining in the puparium and successfully continuing development and emerging in expected time frames, allowing rearing-based confirmation of age, and species identification from adult morphology. Morphological features such as brain, mouthpart, and leg development have been successfully visualized in calliphorid pupae; ${ }^{65}$ however, the puparium limits resolution due to absorption of light and thus limits penetration of light into the insect itself. The method holds promise but requires refinement for extensive use in casework.

\section{Hyperspectral imaging}

The ability to analyze specimens nondestructively is also provided using hyperspectral imaging, a technique used in other areas of forensics ${ }^{66-68}$ and in agriculture. ${ }^{69}$ This method allows specimens to be analyzed either live or preserved in a noninvasive manner, utilizing the technique to provide spatial and spectral information regarding a specimen. Preliminary work assessing the validity of this approach to the analysis of entomological specimens has been conducted using pupae of Chrysomya rufifacies and Calliphora dubia. Specimens reared at $24^{\circ} \mathrm{C}$ and $30^{\circ} \mathrm{C}$ were imaged daily to provide data for predicting age, in conjunction with morphological changes. Hyperspectral imaging allowed determination of pupal age with $>82 \%$ accuracy and also reliably distinguished between the two species based only on spectral data. ${ }^{70}$ The technique has distinct advantages including the portability of the equipment required which, once developed, will allow 
analysis of specimens at the crime scene. Additionally, the nondestructive and noninvasive advantages of the technique allow alternative and/or later reanalysis of evidence. Such advantages place hyperspectral imaging at the forefront of future advances in the forensic field, and there is considerable potential for the approach to be developed as a regular tool in forensic case work. ${ }^{68}$ Problematically, the technique requires the development of a reference database for relevant species prior to implementation in case analysis. It is anticipated, however, that upon further development, hyperspectral imaging will provide a valuable approach to age estimation of all life stages of insect development.

\section{Molecular methods}

Molecular methods form a useful basis for estimation of insect age, as they are based on objective, quantitative data, not subject to the interobserver error associated with morphological methods. In theory, these should be more reliable indicators of insect age. As with morphological methods, the focus is largely on the long-lasting pupal phase.

\section{Steroidogenesis}

Steroidogenesis examines levels of ecdysteroids (polyhydroxylated steroid hormones) produced throughout insect development. Moulting and metamorphosis are triggered by such hormones, and therefore, developmental change can be measured relative to quantitative levels of specific steroids. Ecdysteroid levels were examined in pupae of Protophormia terraenovae based on enzyme immunoassay, and it was shown that with suitable preservation, ecdysteroid peaks could be determined between 36 and 96 hours after pupariation. ${ }^{71}$ This may provide valuable information regarding time of pupariation, to correlate with morphological development observations; however, utility may be limited by state of preservation, for example, when samples have been frozen following collection. Furthermore, conclusions may only be narrowed to quite wide time frames. A more precise method of estimation would be useful, given that the pupal stage may be considerably long.

\section{Gene expression}

During insect development, genes are switched on and off at various times, triggering the synthesis of products including proteins. For a gene to be switched on, the DNA within a cell must first be transcribed as mRNA, called a transcript. Gene expression studies measure the level of transcription at a given point in time. ${ }^{72}$ Measurement of the level of expression of a particular gene over time can provide a useful indication of age of a specimen, as specimens of known age can be examined to build reference data regarding levels of expression expected at various times in development.

Age estimation of Lucilia sericata eggs has been shown to be possible, ${ }^{73}$ successfully aging within 2 hours based on transcript levels of three genes. The use of three genes, rather than one gene alone, allows three expression levels to be compared, providing corroboration and refining age estimations to smaller windows. Other studies ${ }^{59,72}$ have further extended the approach to larval and pupal stages of the same species with success, providing good support for traditional morphology-based methods of age estimation. Pupae, in particular, are useful targets for gene expression-based aging, given the extensive tissue remodeling and cellular proliferation that take place during this stage.

\section{Cuticular hydrocarbons}

On the surface of the insect cuticle is a lipid wax layer of hydrocarbons that function to protect the insect from drying out, provide defense against attack by microorganisms, and may play important roles in behavioral events such as mate selection by acting as pheromones or kairomones. ${ }^{74}$ These hydrocarbons may be either saturated or unsaturated compounds, and have been suggested to be useful in forensic entomology for a number of applications, including determining species identity, determining geographical origin of specimens, and estimating age of individual insects for the purpose of refining ${ }_{\text {min }}$ PMI estimates. ${ }^{75-77}$

Hydrocarbon analysis has been proven useful with forensically significant calliphorids, separating adults of Phormia regina according to population origin and sex, ${ }^{75}$ and identifying empty puparia to species level. ${ }^{77}$ The utility of cuticular hydrocarbon composition to pinpoint larval age in C. rufifacies determined that the method is particularly useful for post-feeding larval age estimation, ${ }^{77}$ mirrored in a study of $L$. sericata showing distinct difference between young and post-feeding larvae. ${ }^{78}$ This is usually limited with respect to morphological changes, so it represents a useful application for the technique. Cuticular hydrocarbons could also be used to help estimate PMI based on weathering of puparia, but this is obviously complicated by the numerous factors that may affect rate and degree of weathering. ${ }^{79}$ Other studies have suggested that insect cuticular hydrocarbons can be used for PMI estimation for egg to 8 -day-old adults $;{ }^{80}$ however, large databases of expected hydrocarbon compositions are required for species of different ages at different locations, given that conspecific populations have been shown to be distinguishable based on hydrocarbon composition. 
The possibility of extending analyses to additionally measure volatile organic compounds released by insects to estimate their age has been proposed ${ }^{81}$ Volatile organic compounds were collected daily throughout larval and pupal phase and analyzed using headspace solid-phase microextraction and gas chromatography-mass spectrometry, and profiles were shown to carry in quantity and composition. While promising initial results were reported for C. vicina, the effect of age and genetic factors, as well as environmental factors (temperature, diet, geoclimate), requires further investigation. In addition, some compounds are produced by the insects, some by the corpse itself, and some by bacteria, so the source of emission needs to be clarified. ${ }^{81}$

\section{The future}

Forensic entomology has become an integral technique for the forensic sciences, providing important information for the investigator regarding time of death. This is dependent initially on examination of the assemblage of insects present, followed by accurate identification, and then refinement of minimum age of insects based on knowledge of developmental rates and ambient temperatures to calculate physiological time. This entire process is limited greatly by lack of data regarding developmental rates in the plethora of decomposition environments that may be encountered, including burials, wrapping, enclosure in vehicles, and aquatic submersion, plus the numerous other complicating variables including drug presence in remains, clothing, rainfall, and humidity. Of all the variables requiring consideration in ${ }_{\min } \mathrm{PMI}$ estimation, temperature is fundamental and is the best studied factor, but there remains a need for significant study into the effect of other variables.

The current methods utilized for ${ }_{\text {min }}$ PMI estimation such as thermal summation and isomegalen/isomorphen diagrams suffer limitations, and as such, several new approaches have been suggested and preliminary work undertaken. But ultimately, entomology is a locality-specific science, and techniques must be thoroughly examined for reliability and utility in all geographic regions of use with all potentially encountered species. Currently, work has focused largely on calliphorids as the first colonizers, but even data gathered for these species requires consideration of numerous biotic and abiotic factors to ensure it is reliable and repeatable and thus suitable for use in legal proceedings. Ultimately, the most reliable methods for estimation will likely be corroborated using multidisciplinary approaches, for example, the use of gene expression, and external and internal morphology to estimate the age of a pupa in conjunction with ExLAC or thermal summation.
In recent times, a number of approaches to age estimation of insect evidence have been proposed and assessed in preliminary validation studies that appear to offer considerable advances in the accuracy of age determination. However, all require substantial development prior to application in standard investigative practice of forensic cases. Further research and establishment of relevant reference data for application is required and warranted in the case of techniques such as hyperspectral imaging, gene expression, and ExLAC.

There are numerous factors that will induce error into ${ }_{\min } \mathrm{PMI}$ calculations, and fundamental to all conclusions is an awareness, and acknowledgment, that biological data, and organisms themselves, are subject to variation. It is unlikely that a one-size, easy-answer approach will be applicable, as each life stage has different features, and each case introduces a new range of challenges, whether they are factors affecting the development of the insect at the crime scene, altered succession patterns, or human-induced challenges such as preservation errors or damage of specimens. A flexible, but scientifically sound and well-tested approach, that encompasses variables as much as possible, but acknowledges shortfalls, is the model that forensic entomologists are ultimately working toward in the provision of ${ }_{\min } \mathrm{PMI}$ estimates for forensic purposes.

\section{Disclosure}

The authors report no conflicts of interest in this work.

\section{References}

1. Amendt J, Richards CS, Campobasso CP, Zehner R, Hall MRJ. Forensic entomology: applications and limitations. Forensic Science, Medicine, and Pathology. 2011;7(4):379-392.

2. Greenberg B. Flies as forensic indicators. Journal of Medical Entomology. 1991;28(5):565-577

3. Tomberlin JK, Mohr R, Benbow ME, Tarone AM, VanLaerhoven SL. A road map for bridging basic and applied research in forensic entomology. Annual Review of Entomology. 2011;56:401-421.

4. Morris B, Dadour I. Forensic entomology: the use of insects in legal cases. In: Freckelton I, Selby H, editors. Expert Evidence. Sydney: Law Book Company; 2005.

5. Wells JD, Greenberg B. Interaction between Chrysomya rufifacies and Cochliomyia macellaria (Diptera: Calliphoridae): the possible consequences of an invasion. Bulletin of Entomological Research. 1992;82:133-137.

6. Putman R. Dynamics of the blowfly, Calliphora erythrocephala, within carrion. Journal of Animal Ecology. 1977;46:853-866.

7. Voss SC, Spafford H, Dadour IR. Annual and seasonal patterns of insect succession on decomposing remains at two locations in Western Australia. Forensic Science International. 2009;193:26-36.

8. Matuszewski S, Bajerlein D, Konwerski S, Szpila K. Insect succession and carrion decomposition in selected forests of Central Europe. Part 2: Composition and residency patterns of carrion fauna. Forensic Science International. 2010;195:42-51.

9. Fuller M. The insect inhabitants of carrion: a study in animal ecology Bulletin of the Australian Council for Scientific and Industrial Research. 1934;82:1-62. 
10. Matuszewski S, Frątczak K, Konwerski S, et al. Effect of body mass and clothing on carrion entomofauna. International Journal of Legal Medicine. 2015:1-12.

11. Nassu MP, Thyssen PJ, Linhares AX. Developmental rate of immatures of two fly species of forensic importance: Sarcophaga (Liopygia) ruficornis and Microcerella halli (Diptera: Sarcophagidae). Parasitology Research. 2014;113(1):217-222.

12. Catts E, Goff M. Forensic entomology in criminal investigations. Annual Review of Entomology. 1992;37(4):253-272.

13. Introna F, Altamura B, Dellerba A, Dattoli V. Time since death definition by experimental reproduction of Lucilia sericata cycles in growth cabinet. Journal of Forensic Sciences. 1989;34(2):478-480.

14. Goff ML. Estimation of postmortem interval using arthropod development and successional patterns. Forensic Science Reviews. 1993;5: 81-94.

15. Amendt J, Krettek R, Niess C, Zehner R, Bratzke H. Forensic entomology in Germany. Forensic Science International. 2000;113(1-3): 309-314.

16. Dadour I, Cook D, Fissioli N, Bailey W. Forensic entomology: application, education and research in Western Australia. Forensic Science International. 2001;120:48-52.

17. Richards CS, Paterson ID, Villet MH. Estimating the age of immature Chrysomya albiceps (Diptera: Calliphoridae), correcting for temeprature and geographic latitude. International Journal of Legal Medicine. 2008;122:271-279.

18. Greenberg B, Kunich JC. Entomology and the Law: Flies as Forensic Indicators. Cambridge, UK: Cambridge University Press; 2002.

19. Nabity P, Higley L, Heng-Moss T. Effects of temperature on development of Phormia regina (Diptera: Calliphoridae) and use of developmental data in determining time intervals in forensic entomology. Journal of Medical Entomology. 2006;43(6):1276-1286.

20. Richards CS, Villet MH. Data quality in thermal summation development models for forensically important blowflies. Medical and Veterinary Entomology. 2009;23(3):269-276.

21. Baque M, Filmann N, Verhoff M, Amendt J. Establishment of developmental charts for the larvae of the blow fly Calliphora vicina using quantile regression. Forensic Science International. 2015;248:1-9.

22. Grassberger M, Reiter C. Effect of temperature on Lucilia sericata (Diptera: Calliphoridae) development with special reference to the isomegalen and isomorphen-diagram. Forensic Science International. 2001;120(1-2):32-36.

23. Wells J, LaMotte L. Estimating maggot age from weight using inverse prediction. Journal of Forensic Sciences. 1995;40:585-590.

24. Dadour IR, Cook DF, Wirth N. Rate of development of Hydrotaea rostrata under summer and winter (cyclic and constant) temperature regimes. Medical and Veterinary Entomology. 2001;15(2): $177-182$.

25. Wagner TL, Wu H-I, Sharpe PJH, Schoolfield RM, Coulson RN. Modeling insect development rates: a literature review and application of a biophysical model. Annals of the Entomological Society of America. 1984;77(2):208-225.

26. Campbell A, Frazer BD, Gilbert N, Gutierrez AP, Mackauer M. Temperature requirements of some aphids and their parasites. Journal of Applied Ecology. 1974;11(2):431-438.

27. Briere J-F, Pracros P, Le Roux A-Y, Pierre J-S. A novel rate model of temperature-dependent development for arthropods. Environmental Entomology. 1999;28(1):22-29.

28. Ikemoto T, Takai K. A new linearized formula for the law of total effective temperature and the evaluation of line-fitting methods with both variables subject to error. Environmental Entomology. 2000;29: 671-682.

29. Lactin D, Holliday D, Johnson L, Craigen R. Improved rate model of temperature-dependent development by arthropods. Environmental Entomology. 1995;24(1):68-75.

30. Voss SC, Spafford H, Dadour IR. Temperature-dependent development of Nasonia vitripennis on five forensically important carrion fly species. Entomologia Experimental et Applicata. 2010;135(1):37-47.
31. Voss SC, Spafford H, Dadour IR. Temperature-dependent development of Tachinaephagus zealandicus Ashmead (Hymenoptera: Encyrtidae), on five forensically important carrion fly species. Medical and Veterinary Entomology. 2010;24(2):189-198.

32. Reibe-Pal S, Madea B. Calculating time since death in a mock crime case comparing a new computational method (ExLAC) with the ADH method. Forensic Science International. 2015;248:78-81.

33. Reibe S, Doetinchem P, Madea B. A new simulation-based model for calculating post-mortem intervals using developmental data for Lucilia sericata (Dipt.: Calliphoridae). Parasitology Research. 2010; 107(1):9-16.

34. Logan J, Woolkind D, Hoyt S, Tanigoshi L. An analytic model for description of temperature dependent rate phenomena in arthropods. Environmental Entomology. 1976;5:1133-1140.

35. Zahiri B, Fathipour Y, Khanjani M, Moharramipour S, Zalucki MP. Preimaginal development response to constant temperatures in Hypera postica (Coleoptera: Curculionidae): picking the best model. Environmental Entomology. 2010;39(1):177-189.

36. Amendt J, Campobasso C, Gaudry E, Reiter C, LeBlanc H, Hall M. Best practice in forensic entomology - standards and guidelines. International Journal of Legal Medicine. 2007;121:90-104.

37. Anderson GS. Minimum and maximum development rates of some forensically important Calliphoridae (Diptera). Journal of Forensic Sciences. 2000;45(4):824-832.

38. Byrd JH, Butler JF. Effects of temperature on Chrysomya rufifacies (Diptera: Calliphoridae) development. Journal of Medical Entomology. 1997;34(3):353-358.

39. Richards C, Crous K, Villet M. Models of development for blowfly sister species Chrysomya chloropyga and Chrysomya putoria. Medical and Veterinary Entomology. 2009;23:56-61.

40. Tomberlin JK, Adler PH, Myers HM. Development of the black soldier fly (Diptera: Stratiomyidae) in relation to temperature. Environmental Entomology. 2009;38(3):930-934.

41. Voss SC, Cook DF, Wei-Feng H, Dadour IR. Survival and development of the forensically important blow fly, Calliphora varifrons (Diptera: Calliphoridae) at constant temperatures. Forensic Science, Medicine, and Pathology. 2014;10(3):314-321.

42. Honek A. Geographical variation in thermal requirements for insect development. European Journal of Entomology. 1996;93:303-312.

43. McWatters HG, Saunders DS. The influence of each parent and geographic origin on larval diapause in the blow fly, Calliphora vicina. Journal of Insect Physiology. 1996;42(8):721-726.

44. Gallagher MB, Sandhu S, Kimsey R. Variation in developmental time for geographically distinct populations of the common green bottle fly, Lucilia sericata (Meigen). Journal of Forensic Sciences. 2010; 55(2):438-442.

45. Hu Y, Yuan X, Zhu F, Lei C. Development time and size-related traits in the oriental blowfly, Chrysomya megacephala along a latitudinal gradient from China. Journal of Thermal Biology. 2010;35:366-371.

46. Hwang CC, Turner BD. Small-scaled geographical variation in life history traits of the blowfly Calliphora vicina between rural and urban populations. Entomologia Experimental et Applicata. 2009;132: 218-224.

47. Liu S-S, Zhang G-M, Zuh J. Influence of temperature variations on rate of development in insects: analysis of case studies from entomological literature. Annals of the Entomological Society of America. 1995; 88(2):107-119.

48. Niederegger S, Pastuschek J, Mall G. Preliminary studies of the influence of fluctuating temperatures on the development of various forensically relevant flies. Forensic Science International. 2010;199(1-3):72-78.

49. Warren JA, Anderson GS. Effect of fluctuating temperatures on the development of a forensically important blow fly, Protophormia terraenovae (Diptera: Calliphoridae). Environmental Entomology. 2013;42:167-172.

50. Al-Saffar ZY, Grainger JNR, Aldrich J. Temperature and humidity affecting development, survival and weight loss of the pupal stage of Drosophila melanogaster, and the influence of alternating temperature on the larvae. Journal of Thermal Biology. 1996;21(5-6):389-396. 
51. Nabity P, Higley L, Heng-Moss T. Light-induced variability in development of forensically important blow fly Phormia regina (Diptera: Calliphoridae). Journal of Medical Entomology. 2007;44(2):351-358.

52. Zuha R, Razak T, Ahmad N, Omar B. Interaction effects of temperature and food on the development of forensically important fly, Megaselia scalaris (Loew) (Diptera: Phoridae). Parasitology Research. 2012;111(5):2179-2187.

53. Clark K, Evans L, Wall R. Growth rates of the blowfly, Lucilia sericata, on different body tissues. Forensic Science International. 2006; 156(2-3):145-149.

54. Ireland S, Turner B. The effects of larval crowding and food type on the size and development of the blowfly, Calliphora vomitoria. Forensic Science International. 2006;159(2-3):175-181.

55. Richards C, Villet M. Factors affecting the accuracy and precision of thermal summation models of insect development used to estimate postmortem intervals. International Journal of Legal Medicine. 2008;122: 401-408.

56. Green P, Simmonds M, Blaney W. Diet nutriment and rearing density affect the growth of black blowfly larvae, Phormia regina (Diptera: Calliphoridae) European Journal of Entomology. 2003;100(1):39-42.

57. Brown K, Thorne A, Harvey M. Calliphora vicina (Diptera: Calliphoridae) pupae: a timeline of external morphological development and a new age and PMI estimation tool. International Journal of Legal Medicine. 2015;129(4):835-850.

58. Richards CS, Simonsen TJ, Abel RL, Hall MJR, Schwyn DA, Wicklein M. Virtual forensic entomology: improving estimates of minimum postmortem interval with 3D micro-computed tomography. Forensic Science International. 2012;220(1):251-264.

59. Tarone AM, Foran DR. Gene expression during blow fly development: improving the precision of age estimates in forensic entomology. Journal of Forensic Sciences. 2011;56:S112-S122.

60. Villet MA, Amendt J. Advances in entomological methods for death time estimation. In: Turk EE, editor. Forensic Pathology Reviews, Volume 6 New York: Humana Press; 2011

61. Day DW, Wallman JF. Width as an alternative measurement to length for post-mortem interval estimations using Calliphora augur (Diptera: Calliphoridae) larvae. Forensic Sceicne International. 2006; 159(2-3):158-167.

62. Gennard DE. Forensic Entomology: An Introduction. Chichester: Wiley; 2007.

63. Castner JL. General entomology and insect biology. In: Byrd JH, Castner JL, editors. Forensic Entomology: The Utility of Arthropods in Legal Investigations: Boca Raton, FL: CRC Press; 2010:17-38.

64. Davies K, Harvey ML. Internal Morphological Analysis for age estimation of blow fly pupae (Diptera: Calliphoridae) in postmortem interval estimation. Journal of Forensic Sceinces. 2013;58(1):79-84

65. Brown K, Harvey M. Optical coherence tomography: age estimation of Calliphora vicina pupae in vivo? Forensic Science International. 2014;242:157-161.

66. Edelman G, van Leeuwen TG, Aalders MCG. Hyperspectral imaging for the age estimation of blood stains at the crime scene. Forensic Science International. 2012;223:72-77.
67. Reed G, Savage K, Edwards D, Daeid NN. Hyperspectral imaging of gel pen inks: an emerging tool in document analysis. Science and Justice. 2014;54:71-80.

68. Edelman GJ, Gaston E, van Leeuwen TG, Cullen PJ, Aalders MCG. Hyperspectral imaging for non-contact analysis of forensic traces. Forensic Science International. 2012;223:28-39.

69. Nansen C, Macedo T, Swanson R, Weaver DK. Use of spatial structure analysis of hyperspectral data cubes for detection of insect-induced stress in wheat plants. International Journal of Remote Sensing. 2009; 30(10):2447-2464.

70. Magni PA, Voss SC, Nansen C, Flematti G, Dadour I. Aging Blowfly Pupae Using Hyperspectral Imaging: Another Tool in the Forensic Toolbox. Orlando, FL: American Academy for Forensic Sciences; 2015.

71. Gaudry E, Blais C, Maria A, Dauphon-Villemant C. Study of steroidogenesis in pupae of the forensically important blow fly Protophormia terraenovae (Robineau-Desvoidy) (Diptera: Calliphoridae). Forensic Science International. 2006;160(1):27-34.

72. Boehme P, Spahn P, Amendt J, Zehner R. Differential gene expression during metamorphosis: a promising approach for age estimation of forensically important Calliphora vicina pupae. International Journal of Legal Medicine. 2013;127(1):243-249.

73. Tarone AM, Jennings KC, Foran DR. Aging blowfly eggs using gene expression: a feasibility study. Journal of Forensic Sciences. 2007; 52(6):1350-1354.

74. Pechal JL, Moore H, Drijfhout F, Benbow ME. Hydrocarbon profiles throughout adult Calliphoridae aging: a promising tool for forensic entomology. Forensic Science International. 2014;245:65-71.

75. Byrne AL, Camann MA, Cyr TL, Catts EP, Espelie KE. Forensic implications of biochemical differences among geographic populations of the black blowfly, Phormia regina (Meigen). Journal of Forensic Sciences. 1995;40(3):372-377.

76. Zhu GH, Ye GY, Hu C, Xu XH, Li K. Developmental changes of cutcular hydrocarbons in Chrysomya rufifacies larvae: potential for determining larval age. Medical and Veterinary Entomology. 2006; 20(4):438-444.

77. Ye G, Li K, Zhu J, Zhu G, Hu C. Cuticular hydrocarbon composition in pupal exuviae for taxonomic ifferentiation of six necrophagous flies. Journal of Medical Entomology. 2007;44(3):450-456.

78. Moore HE, Adam CD, Drijfhout FP. Potential use of hydrocarbons for aging Lucilia sericata blowfly larvae to establish the post-mortem interval. Journal of Forensic Sciences. 2013;58(2):404-412.

79. Zhu GH, Xu XH, Yu XJ, Zhang Y, Wang JR. Puparial case hydrocarbons of Chrysomya megacephala as an indicator of the post-mortem interval. Forensic Science International. 2007;169(1):1-5.

80. Roux O, Gers C, Kegal L. Ontogenetic study of three Calliphoridae of forensic importance through cuticular hydrocarbon analysis. Medical and Veterinary Entomology. 2008;22(4):309-317.

81. Frederickx C, Dekeirsschieter J, Brostaux Y, Wathelet J-P, Verheggen FJ, Haubruge E. Volatile organic compounds released by blowfly larvae and pupae: new perspectives in forensic entomology. Forensic Science International. 2012;219:1-3.
Research and Reports in Forensic Medical Science

\section{Publish your work in this journal}

Research and Reports in Forensic Medical Science is an international, peer-reviewed, open access journal publishing original research, reports, reviews and commentaries on all areas of forensic medical science. The manuscript management system is completely online and includes a

\section{Dovepress}

very quick and fair peer-review system. Visit http://www.dovepress.com/ testimonials.php to read real quotes from published authors. 